\section{Óbitos neonatais em região de alta vulnerabilidade do Município de Santos, São Paulo, Brasil: examinando questões assistenciais na perspectiva das mulheres}

\author{
Neonatal deaths in a highly vulnerable area \\ in Santos, São Paulo State, Brazil: examining \\ healthcare issues from women's perspective
} Mortalidad neonatal en una región de alta
vulnerabilidad del municipio de Santos, estado
de São Paulo, Brasil: examinando cuestiones
asistenciales desde la perspectiva de las mujeres
Macarena Urrestarazu Devincenzi 1

Lilia Blima Schraiber 2 doi: 10.1590/0102-311X00081718

\section{Resumo}

O estudo analisou a trajetória de vida e de cuidado de mulheres residentes na zona noroeste do Município de Santos, São Paulo, Brasil, que passaram pela experiência de óbitos neonatais entre janeiro de 2015 a julho de 2016. Realizou-se triangulação de dados de documentos da seção de vigilância, diários de campo de visitas aos serviços e entrevistas com as mulheres. Essas constituíram o principal eixo da produção de dados empíricos, por meio de narrativas sobre a história sexual e reprodutiva, cuidado pré-natal, ao parto e a experiência do óbito neonatal. De 15 casos elegíveis, entrevistaram-se oito mulheres, seis com mais e duas com menos de 30 anos, negras, naturais de Santos, em ocupações de baixa qualificação. Como resultados do conjunto dos dados observou-se: (1) históricos de gestações não planejadas e diversos fatores de risco gestacionais; (2) reconhecimento pelas mulheres de que tiveram bom acesso aos serviços de saúde; (3) questionamentos relativos a: necessidade de exames e retornos, valorização de intercorrências, esclarecimento de condutas e encaminhamentos; (4) prematuridade, envolvida em todos os casos; (5) sobre o parto relatam dor, abandono e transferência por falta de leito em UTI neonatal; (6) falta de integração entre os níveis de atenção; e (7) após o óbito, abordagens restritas e pouco orientadas para uma atenção integral relativas ao evento do óbito neonatal. Conclui-se que embora o cuidado pré-natal tenha sido bem avaliado pelas mulheres, não se verifica, quanto à experiência do óbito neonatal, um cuidado integral para essas mulheres, com diálogo e oferta de métodos contraceptivos mais adequados ao seu histórico, ou relativamente ao sofrimento mental resultante dessas experiências.

\author{
Correspondência \\ M. U. Devincenzi \\ Universidade Federal de São Paulo. \\ Rua Silva Jardim 136, Santos, SP 11015-020, Brasil. \\ macarena.nut@gmail.com \\ 1 Universidade Federal de São Paulo, Santos, Brasil. \\ 2 Faculdade de Medicina, Universidade de São Paulo, São Paulo, \\ Brasil.
}




\section{Introdução}

A atenção básica por intermédio da Estratégia Saúde da Família tem contribuído para a prevenção de complicações na gestação pelo maior acesso da mulher aos serviços de saúde e vínculo com os profissionais. No entanto, as dificuldades para a articulação de ações em rede e intersetoriais prejudicam o acompanhamento integral do pré-natal e das necessidades das mulheres, aumentando o risco de óbitos infantis, que permanecem como desafio quanto à compreensão de seus determinantes sociais, especialmente no período peri e neonatal 1.

Assim sendo, a se respeitar o princípio da integralidade previsto para o Sistema Único de Saúde (SUS) 2, deveríamos encontrar não apenas uma atenção mais global na assistência de cada serviço, mas também uma articulação entre os diferentes serviços, como parte da preocupação para garantir a complementaridade e longitudinalidade do cuidado.

O estudo nacional de base hospitalar conduzido entre 2011 e 2012 no Brasil, com puérperas e seus recém-nascidos, verificou taxa de mortalidade neonatal de 11,2 por mil nascidos vivos, sendo que a prematuridade e o baixo peso ao nascer foram os principais fatores associados ao óbito neonatal. Para a sua redução os autores apontam a qualificação da assistência pré-natal, com o controle das infecções e dos riscos na gravidez, com ações efetivas e oportunas em serviço com nível adequado de complexidade, e a melhoria da atenção hospitalar ao parto e nascimento, com práticas baseadas em evidências científicas 3 .

Entretanto, da perspectiva do conjunto dos determinantes sociais, pouco tem sido explorado acerca do que essas experiências de óbito neonatal representam para as mulheres e de quais vulnerabilidades estão envolvidas, lembrando que estas podem ser ligadas ao social, aos programas de saúde ou a características mais individuais ${ }^{4}$.

Quanto aos comitês de prevenção ao óbito materno e infantil, apesar de promoverem a investigação e discussão dos casos com a participação de profissionais de todos os níveis de atenção à saúde, com avaliação de processos de trabalho e de organização dos serviços, um estudo realizado no Estado de São Paulo verificou que menos da metade relaciona suas ações com mudanças na assistência 5 , e mesmo na região do estado com maior avanço na implementação da Rede Cegonha, as práticas de vigilância sanitária e assistência continuam fragmentadas 6 .

No que se refere à mulher, escutar sua perspectiva sobre necessidades e cuidados em saúde 7,8 e sobre a própria experiência do óbito infantil 9,10 pode ampliar a compreensão do fenômeno e das vulnerabilidades a que estão expostas, apontando caminhos para uma efetiva integralidade nas práticas profissionais.

Este trabalho busca conhecer as experiências de mulheres que vivenciaram óbitos neonatais numa região de vulnerabilidade do Município de Santos, São Paulo, Brasil, examinando-as da perspectiva da vulnerabilidade das mulheres e da integralidade da atenção à saúde envolvida.

\section{Método}

Numa análise espacial da mortalidade neonatal no Estado de São Paulo verificou-se um valor de 8,7 por mil nascidos vivos, entre os anos de 2006 a 2010. A microrregião de Santos alcançou o valor de 11,51 por mil nascidos vivos, com alta prioridade de atenção e intervenção 11 .

O Município de Santos, apesar de ocupar o sexto lugar do ranking das cidades brasileiras com o melhor Índice de Desenvolvimento Humano, apresenta desigualdade de desenvolvimento de suas regiões. A orla constituída pela faixa litorânea, que abriga a população de maior nível socioeconômico; a área central, mais antiga, contígua à zona portuária; a área dos morros, que remonta a ocupação portuguesa no período colonial; e a zona noroeste, com adensamento populacional de baixa renda, cuja ocupação data da década de 1960, próxima às atividades retroportuárias, com moradias subnormais que ocupam as margens dos rios da área, transformando-se numa das maiores favelas e bolsão de pobreza da região 12 . Esse território de alta vulnerabilidade social e ambiental foi a localidade de realização do presente trabalho. 
O estudo foi aprovado junto à Comissão de Pesquisa e Intervenção da Secretaria Municipal de Saúde de Santos e Comitê de Ética em Pesquisa da Faculdade de Medicina da Universidade de São Paulo, sob o número 1.897.208.

Em termos de seu desenho, este foi centrado na recuperação das experiências das mulheres que vivenciaram óbitos neonatais, ocorridos no período de janeiro de 2015 a julho de 2016. Para tal, utilizou-se histórias de vida 13,14,15 com ênfase desde a adolescência, na vida sexual e reprodutiva da mulher, explorando-se: experiência da vida familiar na infância; relações amorosas, conjugalidade e reprodução; o acompanhamento na gestação; a atenção ao parto e ao recém-nascido; os cuidados pós-óbito neonatal, perspectivas futuras de vida e de cuidado à saúde da mulher. É importante destacar que essa exploração foi baseada em indagações amplas, estimulando a livre narrativa.

Conforme recomendado pela literatura acerca das histórias de vida, seus dados foram complementados por duas outras fontes: dados documentais e dados recolhidos junto a profissionais de serviços de saúde em visitas registradas em diário de campo.

Na produção dos dados documentais, no primeiro semestre de 2017, realizou-se o levantamento dos óbitos infantis do município nos anos de 2015 e 2016 junto à Seção de Vigilância à Mortalidade Materno Infantil (SEVIG-MMI), da Secretaria Municipal de Saúde de Santos, com base nos sistemas de informação sobre mortalidade (SIM) e nascidos vivos (SINASC), Declaração de Nascido Vivo (DNV), Declaração de Óbito (DO) e bancos de dados próprios da seção. Verificaram-se fichas de investigação de óbito infantil preconizadas pelo Ministério da Saúde, registros e demais documentos do processo de investigação dos óbitos, levantando informações relacionadas aos serviços de saúde de atenção ao pré-natal, parto e criança, bem como as visitas domiciliares realizadas pelos profissionais de saúde da rede, à época do óbito. Registrou-se também a classificação de evitabilidade feita pelo comitê municipal, baseada na lista brasileira de causas de mortes evitáveis por intervenções do SUS em menores de cinco anos: Grupo 1: Causas evitáveis: 1.2 - Reduzíveis por adequada atenção à mulher na gestação, parto, feto e ao recém-nascido, sendo: 1.2.1 - Mortes reduzíveis por adequada atenção à mulher na gestação; 1.2.2 - Mortes reduzíveis por adequada atenção à mulher no parto; 1.2.3 - Mortes reduzíveis por adequada atenção ao feto e ao recém-nascido 16.

Nesse levantamento, após a identificação e seleção dos óbitos neonatais da região da zona noroeste do município, foram selecionados os casos ocorridos apenas entre janeiro de 2015 a julho de 2016, cujas mulheres pudessem ser, então, entrevistadas ao menos um ano após o ocorrido, o que aconteceu no segundo semestre de 2017. Tal procedimento deveu-se ao fato de que sendo a experiência de óbito neonatal um evento complexo e sensível para as mulheres, entendeu-se que após um ano elas falariam com mais tranquilidade sobre o ocorrido. Conduziu-se, então, a análise documental específica desses casos.

Nessa etapa, os critérios de exclusão foram casos de óbitos de filhos de mães adolescentes, já que se pretendia na próxima etapa ter acesso às mulheres e o fato de serem adolescentes exigiria autorização de responsáveis e abordagem especial; e casos de óbitos por malformações, por considerar que nestes a dimensão biológica é a principal envolvida no desfecho.

No período estudado, 30 óbitos infantis foram constatados na zona noroeste, dos quais 21 foram óbitos neonatais. Desses, foram excluídos quatro por malformações e dois por terem sido situações com mulheres adolescentes, resultando em 15 casos de mulheres elegíveis para este trabalho.

Por fim, outra complementação dos dados foi pelo contato com as unidades básicas de saúde de referência dos casos de óbito neonatal eleitos, que totalizaram seis unidades distintas, para consulta aos prontuários e conversas com as equipes de saúde, no sentido de caracterizar a atenção recebida no pré-natal, encaminhamento ao parto e posterior seguimento em puerpério. O material empírico dessas visitas, tanto documental quanto as conversas com os profissionais de saúde, foi registrado em diários de campo. A visita aos serviços de saúde também serviu para a localização e acesso às mulheres que seriam entrevistadas.

Todas as entrevistas foram realizadas pela pesquisadora, em local de preferência da mulher para garantir privacidade e confidencialidade, somente após a leitura e assinatura do Termo de Consentimento Livre e Esclarecido. Foram gravadas e transcritas, sendo ainda verificadas quanto à fidelidade da transcrição.

A análise do material obtido nas entrevistas seguiu a dupla leitura das narrativas: a leitura individual que permite a impregnação do pesquisador em termos da compreensão do relato obtido como a 
história daquele indivíduo; e a leitura transversal do conjunto das narrativas para fins de identificar convergências ou diversidade das experiências individuais no contexto social e comunitário, dos sujeitos que pertencem a uma mesma base territorial. Em ambas as leituras extraem-se temas que, ou constituem respostas ao roteiro da entrevista, ou são situações originais do relato. Essa análise semântica diz respeito ao conteúdo das narrativas, sendo produto da chamada análise de conteúdo 17.

As três fontes de dados foram articuladas na análise final, estruturada nas seguintes categorias analíticas: As Mulheres, Vulnerabilidades, Gestação e Riscos; Assistência Pré-Natal: Domínio de Competência e Relações Público-Privado; O Parto; E a Vida Continua...: A Mulher e seu Cuidado no Pós-Parto.

\section{Resultados}

Das 15 mulheres elegíveis, houve duas mudanças de endereço para outros estados ou municípios, e cinco perdas: duas recusas por telefone no primeiro contato, cujos motivos foram, em um caso, alegação de grande trauma, não querendo retomar o assunto; e em outro, óbito relacionado a violência obstétrica, estando o caso na Justiça, sendo esta a alegação; e três mulheres, que apesar do contato telefônico e apoio dos agentes comunitários de saúde (ACS) que foram até suas casas, não compareceram após três tentativas de encontro agendadas.

Das oito entrevistas, seis foram realizadas nas unidades de saúde e duas no domicílio, com duração média de duas horas cada.

Os dados produzidos estão nos Quadros 1, 2 e 3, sendo que as mulheres foram identificadas por nomes fictícios, seguidos de sua idade e número de ordem da gestação correlata ao óbito neonatal.

Em termos de características sociodemográficas, o grupo de mulheres do estudo é, quanto à cor da pele, negro; residente na zona noroeste há mais de dez anos; em parte com Ensino Fundamental, ou com o Médio completo; de baixa camada social, com mulheres desempregadas ou trabalhando em limpeza, sendo que três recebem benefícios para a complementação da renda e metade vive em casa de familiares (Quadro 1).

Sobre a gestação, chama a atenção que, mesmo fazendo uso de métodos contraceptivos, quase todas elas, por motivos diversos, acabaram tendo gravidez indesejada:

“...aí passei a tomar remédio, tudo direitinho, só que estava me engordando muito, troquei. A médica disse: '15 dias você se cuida, depois tudo ok'. Falei: 'ok... 15 dias'. Engravidei, engravido muito fácil... [risos]. Aí fui eu lá no Dr. [do alto risco] de novo. Ele: 'de novo!!!'. 'Doutor, eu não sei o que aconteceu...' [risadas]. 'Eu troquei de remédio, doutor.' 'Puxa, você sabe que você não pode'. Falei: 'tá bom”' (Milena,I33,G6).

“...aí ele me passou um outro comprimido, que não lembro o nome agora... falei: 'não está adiantando, doutor, a minha pressão está indo muito alta. E eu tenho medo mesmo assim de pegar outra gravidez'. Aí ele falou: 'então vamos fazer o seguinte, você continua usando camisinha e vamos então parar um pouquinho'. Aí continuei usando camisinha e não sei o que aconteceu... que o bebê veio" (Silmara,I29,G2).

Também revelaram preocupação com a gestação. Katia,I33,G4 vivia numa situação muito precária, com problemas com o marido quando descobriu a gravidez de gêmeos: “...tem dois aqui. Aí virou e era mesmo... Meu Deus, agora minha vida acabou, porque vou ser sincera, meus planos era viver bem com o segundo marido, mas não ter mais filho com ele, que eu sabia que não era pra mim, que ele ia aprontar alguma. Ai eu saí de lá... não sabia para onde eu ia... sabe quando você fica desesperada?".

Ainda relativamente ao Quadro 1, observamos fatores de risco presentes antes da gestação, além das condições sociodemográficas desfavoráveis, os relacionados a características individuais, tais como: idade superior a 35 anos, baixa escolaridade, situação conjugal insegura, conflitos familiares, peso pré-gestacional superior a $75 \mathrm{~kg}$. Também relacionados à história reprodutiva anterior, com casos de abortamento, parto pré-termo e síndrome hipertensiva. E quanto às condições que surgiram no decorrer da gestação, observamos ganho ponderal inadequado, diabetes gestacional, hemorragias e insuficiência istmo-cervical.

Relativamente aos serviços de saúde em Santos e ao acesso das mulheres, o pré-natal de baixo risco é realizado na atenção básica, tanto em unidades básicas de saúde, com ginecologistas, como em unidades de saúde da família, com médicos de família, pois coexistem os dois modelos de atenção. Muitos usuários se referem às unidades como "policlínicas" por terem sido assim denominadas no passado. Há um serviço de atenção especializada, o Instituto da Mulher e Gestante, que recebe os 


\section{Quadro 1}

Identificação, história reprodutiva e cuidado pré-natal das mulheres que vivenciaram o óbito neonatal. Zona noroeste de Santos, São Paulo, Brasil, 2015-2016.

\begin{tabular}{|c|c|}
\hline IDENTIFICAÇÃO DA MULHER & HISTÓRIA REPRODUTIVA E CUIDADO PRÉ-NATAL \\
\hline $\begin{array}{l}\text { Katia,I33,G4 } \\
\text { Natural de Santos, preta, } 6 \text { anos de estudos, } \\
\text { casada mas está separada, não está trabalhando } \\
\text { no momento por doença, não recebe pensão dos } \\
\text { filhos e houve interrupção do bolsa família. } \\
\text { Vive na casa que era do pai com dois filhos } \\
\text { maiores, adolescentes. }\end{array}$ & $\begin{array}{l}3 \text { filhos vivos (partos normais). Último parto em } 2011 . \\
\text { IV gestação (gemelar). } \\
\text { Pré-natal: } 4 \text { consultas na atenção básica, encaminhada para pré-natal de alto risco ao } \\
\text { hospital regional de referência por gestação gemelar e diabetes. } \\
\text { Não há registros do pré-natal no hospital. } \\
\text { Nenhum filho foi desejado, tomava anticoncepcional oral ou injetável. }\end{array}$ \\
\hline $\begin{array}{l}\text { Milena,I33,G6 } \\
\text { Natural de Ferraz de Vasconcelos (São Paulo), } \\
\text { preta, Ensino Médio completo, solteira, com } \\
\text { companheiro há } 8 \text { anos, trabalha com carteira } \\
\text { assinada como encarregada de limpeza. } \\
\text { Vive em casa dos fundos (em obras), do sogro, } \\
\text { com companheiro e } 2 \text { filhas. }\end{array}$ & $\begin{array}{l}2 \text { abortos e } 1 \text { óbito neonatal (parto normal). Duas filhas vivas (cesarianas). } \\
\text { Último parto em } 2013 . \\
\text { Histórico de incompetência istmo-cervical e partos prematuros. } \\
\text { VI gestação. } \\
\text { Pré-natal: } 6 \text { consultas no convênio/privado. Identificaram tardiamente colo curto, sem } \\
\text { tempo para fazer cerclagem. Usou pessário, que segurou por mais } 3 \text { semanas. } \\
\text { Não há registros, nem cartão de pré-natal. } \\
\text { Não esperava a gestação, tinha trocado a medicação anticoncepcional, pois estava } \\
\text { engordando. }\end{array}$ \\
\hline $\begin{array}{l}\text { Judite,I36,G4 } \\
\text { Natural de Santos, parda, Ensino Superior } \\
\text { completo (tecnólogo), dona de casa, casada. } \\
\text { Vive em casa própria com marido e filhos. }\end{array}$ & $\begin{array}{l}2 \text { filhos vivos, durante adolescência. Último parto em } 1996 . \\
1 \text { aborto. } \\
\text { IV gestação. } \\
\text { Pré-natal: } 3 \text { consultas na atenção básica e foi encaminhada para atenção especializada, } \\
\text { por obesidade, com } 13 \text { semanas. Teve } 2 \text { consultas no serviço especializado e foi devolvida } \\
\text { para a atenção básica, que quis encaminhá-la novamente e ela procurou o convênio/ } \\
\text { privado. Passou a ir com frequência semanal às consultas, pois teve sangramentos. A } \\
\text { atenção básica manteve vínculo com visitas semanais. } \\
\text { Só há registro das consultas no sistema público. } \\
\text { Fazia uso de anticoncepcional injetável, mas parou pois engordou muito e achava que não } \\
\text { engravidaria, pela gordura e por ter um cisto no ovário. }\end{array}$ \\
\hline $\begin{array}{l}\text { Silmara,I29,G2 } \\
\text { Natural de Santos, parda, Ensino Médio } \\
\text { completo, dona de casa, solteira, com } \\
\text { companheiro há } 5 \text { anos. Recebe Bolsa Família há } \\
3 \text { meses. } \\
\text { Vive em apartamento de conjunto habitacional } \\
\text { com mãe, irmão, companheiro e a filha. }\end{array}$ & $\begin{array}{l}1 \text { filha viva, parto em } 2012 \text {. } \\
\text { Il gestação. } \\
\text { Pré-natal: } 4 \text { consultas na atenção básica, com registro de valores elevados de pressão } \\
\text { arterial, prescrição de medicação e de necessidade de controle da pressão arterial diário. } \\
\text { Com } 15 \text { semanas encaminharam para atenção especializada e de lá para hospital regional } \\
\text { de referência para a gestação de alto risco pela hipertensão. Houve duas internações. Com } \\
27 \text { semanas ficou internada no hospital de referência. } \\
\text { No cartão da gestante e prontuário da unidade só há registro da atenção básica. } \\
\text { Não esperava a gestação, anticoncepcionais estavam aumentando a pressão e o médico } \\
\text { falou para parar um pouco e usar preservativo. }\end{array}$ \\
\hline $\begin{array}{l}\text { Juçara,I29,G2 } \\
\text { Natural de Santos, parda, Ensino Médio } \\
\text { completo, trabalha com carteira assinada como } \\
\text { líder de limpeza, casada. } \\
\text { Vive em casa própria com o marido. }\end{array}$ & $\begin{array}{l}2 \text { abortos, último em } 2014 . \\
\text { Il gestação (informação do cartão da gestante). } \\
\text { Pré-natal: } 6 \text { consultas na atenção básica, início com } 7 \text { semanas, registro no cartão da } \\
\text { gestante. Consta infecção urinária e tratamento. } \\
\text { Planejou as gestações. Sempre usou preservativo e por um tempo associou pílula } \\
\text { anticoncepcional, mas lhe fazia mal e parou. }\end{array}$ \\
\hline
\end{tabular}

(continua) 


\begin{tabular}{|c|c|}
\hline IDENTIFICAÇÃO DA MULHER & HISTÓRIA REPRODUTIVA E CUIDADO PRÉ-NATAL \\
\hline $\begin{array}{l}\text { Roberta,I39,G3 } \\
\text { Natural de Santos, "morena", } 8 \text { anos de estudos, } \\
\text { dona de casa, casada. } \\
\text { Vive em apartamento próprio com o marido. }\end{array}$ & $\begin{array}{l}2 \text { abortos num intervalo de } 7 \text { meses, em } 2013 \text { e } 2014 . \\
\text { III gestação (gemelar). } \\
\text { Pré-natal: } 3 \text { consultas no convênio/privado. Refere internação na maternidade } \\
\text { municipal por sangramento. Em consulta médica posterior identificaram pressão alta e } \\
\text { encaminharam para hospital regional de referência para alto risco, onde ficou internada. } \\
\text { Não há registro das consultas, internações e nem cartão de pré-natal. } \\
\text { Planejou as gestações. Sempre usou pílula anticoncepcional e parou para tentar } \\
\text { engravidar. }\end{array}$ \\
\hline $\begin{array}{l}\text { Jandira,I21,G1 } \\
\text { Natural de Cubatão (São Paulo), branca, } 8 \\
\text { anos de estudos, desempregada, solteira, com } \\
\text { companheiro há } 2 \text { anos. } \\
\text { Vive na casa dos avós maternos e passa algumas } \\
\text { noites na casa da família do companheiro. }\end{array}$ & $\begin{array}{l}\text { Primípara. } \\
\text { Pré-natal: } 5 \text { consultas na atenção básica. Consta infecção urinária, glicemia aumentada em } \\
\text { destaque, aumento de peso de } 8 \mathrm{~kg} \text { em } 3 \text { meses e que foi solicitado teste de tolerância à } \\
\text { glicose. } \\
\text { Refere que teve sangramentos a partir dos } 2 \text { meses de gestação, procurou maternidade } \\
\text { municipal e a mandaram para a atenção básica e de lá novamente para maternidade. Com } \\
\text { cerca de } 5 \text { meses o sangramento aumentou e foi internada. } \\
\text { Só há registros das consultas na atenção básica. } \\
\text { Não esperava a gestação, usava anticoncepcional injetável desde os } 15 \text { anos e parou pois } \\
\text { estava engordando. Passou a usar preservativo. }\end{array}$ \\
\hline $\begin{array}{l}\text { Dalva,I20,G4 } \\
\text { Natural de Maceió (Alagoas), parda, } 8 \text { anos de } \\
\text { estudos, ajudante de cozinha geral, solteira, sem } \\
\text { companheiro. Trabalhando em restaurante, sem } \\
\text { registro e ganha } 1 \text { salário mínimo. Recebe Bolsa } \\
\text { Família há } 1 \text { mês. } \\
\text { Vive com a filha de } 3 \text { anos numa casa alugada, } \\
\text { com uma amiga que tem dois filhos. }\end{array}$ & $\begin{array}{l}3 \text { filhos vivos. Último parto em } 2014 . \\
\text { Histórico de violência por parceiro íntimo do primeiro companheiro, durante adolescência. } \\
\text { Teve dois filhos e fugiu de casa. } \\
\text { IV gestação. } \\
\text { Não fez pré-natal, pois não sabia que estava grávida. } \\
\text { Após a primeira gestação usou anticoncepcional injetável. Todas as gestações foram } \\
\text { indesejadas. }\end{array}$ \\
\hline
\end{tabular}

SUS: Sistema Único de Saúde.

encaminhamentos da atenção básica do município quando são identificados riscos na gestação. E em relação aos hospitais com maternidade, há um municipal localizado na zona noroeste do município e um estadual de referência regional para gestação de alto risco. Ambos atendem exclusivamente pelo SUS. Além de hospitais filantrópicos e privados.

Em geral, o seguimento pré-natal dessas mulheres iniciou em tempo oportuno, com menos de 16 semanas e na atenção básica em saúde pelo SUS. Duas fizeram o acompanhamento em serviço privado e uma não chegou a iniciar o pré-natal, pois desconhecia a gestação.

Juçara,I29,G2 e Jandira,I21,G1 ficaram na atenção básica, mas intercorrências que apresentaram durante a gestação, infecção e sangramento, não foram resolvidas neste nível de atenção e se relacionaram ao parto prematuro.

“...eu vinha fazer o controle, tudo certinho, não perdia uma consulta do pré-natal... tomava todas as injeções certinhas, tudo certinho... oh... eu li muito que se a mulher engravida e ela tiver uma bactéria muito forte ela fica alojada no útero e ela acaba causando uma dilatação que ela acaba tendo um filho prematuro. Que a criança vai crescendo e vai ficando aquele peso. Aí eu fiquei imaginando... pô... como que eu posso estar com infecção... fiz exames, mas a médica falou que eu estava com uma infecção muito forte... que acabou passando para o bebê e para o sangue do bebê, mas será que foi isso?” (Juçara,I29,G2). 


\section{Quadro 2}

Informações da Seção de Vigilância à Mortalidade Materno Infantil (SEVIG-MMI) da Secretaria Municipal de Saúde de Santos sobre o óbito neonatal e classificação de sua evitabilidade. Percepção da mulher sobre o parto e óbito neonatal. Zona noroeste de Santos, São Paulo, Brasil, $2015-2016$.

\begin{tabular}{|c|c|}
\hline $\begin{array}{c}\text { MULHER/PARTO/RECÉM-NASCIDO/ÓBITO NEONATAL/ } \\
\text { EVITABILIDADE DE CADA CASO }\end{array}$ & PERCEPÇÃO DA MULHER SOBRE O PARTO E ÓBITO NEONATAL \\
\hline $\begin{array}{l}\text { Katia,I33,G4 } \\
\text { Parto: cesariana, hospital regional de referência para gestação de } \\
\text { alto risco (SUS). } \\
\text { Recém-nascido: idade gestacional } 36 \text { semanas, gemelar, peso ao } \\
\text { nascer } 2.825 g \text {, Apgar } 8 \text { e 9, sexo feminino. } \\
\text { Sofrimento fetal agudo. Evoluiu com pneumonia e choque séptico. } \\
\text { Óbito com } 7 \text { dias. } \\
\text { Agosto/2015. } \\
\text { Evitabilidade: sim (1.2.3 Atenção ao recém-nascido/1.2.1 Atenção à } \\
\text { gestação). }\end{array}$ & $\begin{array}{l}\text { Na consulta semanal já no final da gestação, no hospital, identificaram } \\
\text { algum problema no ultrassom, internaram e fizeram o parto cesariana. } \\
\text { Ela diz que nasceram grandes, bonitos e perfeitos, mas tiveram as } \\
\text { paradas cardíacas, primeiro o menino e depois a menina, e que ambos } \\
\text { foram para a UTI neonatal. Refere que até hoje não entendeu o que } \\
\text { aconteceu, mas que não foi culpa de ninguém, que tinha de acontecer } \\
\text { e que foi bem assistida. Ficou muito mal após o parto, muito inchada. O } \\
\text { período de UTI a desgastou muito e quando aconteceu o óbito da filha } \\
\text { quis ir embora logo com o outro filho para casa. }\end{array}$ \\
\hline $\begin{array}{l}\text { Milena,133,G6 } \\
\text { Parto: cesariana, hospital do convênio/privado. } \\
\text { Recém-nascido: idade gestacional } 26 \text { semanas, peso ao nascer } \\
710 \mathrm{~g} \text {, Apgar } 4 \text { e } 7 \text {, sexo feminino. } \\
\text { Prematuridade, doença pulmonar da membrana hialina e sepse } \\
\text { neonatal. Óbito com } 13 \text { dias. } \\
\text { Novembro/2015. } \\
\text { Evitabilidade: sim (1.2.3 Atenção ao recém-nascido). }\end{array}$ & $\begin{array}{l}\text { Teve um quadro de hemorragia e foi às pressas para cesariana. Falou } \\
\text { do risco de morte no parto. Médicos falaram que iam tentar salvá-la, } \\
\text { mas que a filha seria difícil. Abriram todo o útero para tirar a bebê. Mas } \\
\text { refere que não tirou o útero, que preservaram e que ela pensou por que } \\
\text { não tirou de uma vez, mas entendeu que não podia naquele momento. } \\
\text { Falou que desta vez sofreu menos com a perda por ter suas duas filhas e } \\
\text { principalmente a menor para cuidar. }\end{array}$ \\
\hline $\begin{array}{l}\text { Judite,I36,G4 } \\
\text { Parto: normal, hospital do convênio/privado. } \\
\text { Recém-nascido: idade gestacional } 20 \text { semanas, peso ao nascer } \\
\text { 380g, Apgar } 1 \text { e 1, sexo masculino. } \\
\text { Prematuridade extrema. Recém-nascido afetado por transtornos } \\
\text { nutricionais maternos (obesidade). Óbito com } 4 \text { horas de vida. } \\
\text { Janeiro/2015. } \\
\text { Evitabilidade: sim (1.2.1 Atenção à gestação). }\end{array}$ & $\begin{array}{l}\text { Teve muitas contrações e dores, mas não sabia como era pois seus filhos } \\
\text { anteriores foram cesarianas. O parto foi normal na sala de pré-parto, } \\
\text { falou que achou que o bebê estava morto, levaram com pressa. E ela } \\
\text { teve de fazer curetagem e foi anestesiada. Depois o marido comentou } \\
\text { que o bebê ficou na incubadora por } 5 \text { horas. Ela e o marido ficaram } \\
\text { muito tristes com o ocorrido. }\end{array}$ \\
\hline $\begin{array}{l}\text { Silmara,129,G2 } \\
\text { Parto: cesariana no Hospital Regional de Itanhaém (SUS). } \\
\text { Recém-nascido: idade gestacional } 27 \text { semanas, peso ao nascer } \\
725 g \text {, Apgar } 2 \text { e 8, sexo masculino. } \\
\text { Enterocolite necrotizante, choque séptico, hipertensão materna. } \\
\text { Óbito com } 20 \text { dias. } \\
\text { Outubro/2015. } \\
\text { Evitabilidade: sim (1.2.1 Atenção à gestação). }\end{array}$ & $\begin{array}{l}\text { Estava internada em hospital regional de referência para gestação } \\
\text { de alto risco e foi transferida de ambulância para o parto em outro } \\
\text { município, por falta de vaga na UTI neonatal. Relatou que foi cesariana, } \\
\text { que ele nasceu pequenininho e roxo e foi direto para a UTI. Só no dia } \\
\text { seguinte foi fazer a estimulação do leite e ia a cada } 2 \text { horas. Relatou a } \\
\text { dificuldade da distância da família e filha de } 3 \text { anos, mas que recebeu } \\
\text { apoio dos profissionais do hospital. Sobre o óbito comentou que } \\
\text { queriam enterrar em Itanhaém, mas sua mãe tinha um plano de funeral } \\
\text { particular que cobriu o traslado para Santos. }\end{array}$ \\
\hline $\begin{array}{l}\text { Juçara,I29,G2 } \\
\text { Parto: normal no hospital/maternidade municipal (SUS). } \\
\text { Recém-nascido: idade gestacional } 27 \text { semanas, peso ao nascer } \\
\text { 1.090g, Apgar } 4 \text { e 6, sexo masculino. } \\
\text { Recém-nascido afetado por corioamnionite, doença da membrana } \\
\text { hialina, fisiometria, choque séptico. Óbito com } 2 \text { dias. } \\
\text { Julho/2015. } \\
\text { Evitabilidade: sim (1.2.1 Atenção à gestação). }\end{array}$ & $\begin{array}{l}\text { Vinha se sentindo úmida e numa manhã tomando banho sentiu sair } \\
\text { o tampão e uma dor forte no pé da barriga. Foi ao hospital e ficou } \\
\text { internada, relata muitas dores, diferentes médicos avaliando, mas que } \\
\text { sentia o bebê mexer. Presenciou violência obstétrica com outra mulher } \\
\text { que estava internada no seu quarto, mas que ela sofreu quieta e calada. } \\
\text { Recebeu medicação para alívio da dor, mas não adiantava. Relata perda } \\
\text { de líquidos, contrações e que fez força no parto. } \\
\text { Entendeu que seu filho era muito prematuro e que seu pulmão não } \\
\text { estava maduro. É muito religiosa e referiu que Deus deu e Deus tirou. }\end{array}$ \\
\hline
\end{tabular}

(continua) 


\begin{tabular}{|c|c|}
\hline $\begin{array}{c}\text { MULHER/PARTO/RECÉM-NASCIDO/ÓBITO NEONATAL/ } \\
\text { EVITABILIDADE DE CADA CASO }\end{array}$ & PERCEPÇÃO DA MULHER SOBRE O PARTO E ÓBITO NEONATAL \\
\hline $\begin{array}{l}\text { Roberta,I39,G3 } \\
\text { Parto: cesariana, hospital do convênio/privado. } \\
\text { Recém-nascido: idade gestacional } 29 \text { semanas, gemelar, peso ao } \\
\text { nascer } 960 \text { g, Apgar } 8 \text { e 9, sexo feminino. } \\
\text { Insuficiência respiratória do recém-nascido, imaturidade extrema, } \\
\text { recém-nascido afetado por transtorno materno hipertensivo. Óbito } \\
\text { com } 27 \text { dias. } \\
\text { Janeiro/2016. } \\
\text { Evitabilidade: sim (1.2.1 Atenção à gestação). }\end{array}$ & $\begin{array}{l}\text { Estava internada em hospital regional de referência para gestação de } \\
\text { alto risco e foi transferida de ambulância para outro hospital para fazer } \\
\text { o parto, por causa de vagas na UTI neonatal, pois eram gemelares. Ficou } \\
\text { muito nervosa e preocupada com a transferência, teve medo de morrer. } \\
\text { Relata que as filhas nasceram e foram levadas para a UTI. Reconhece } \\
\text { prematuridade e o risco de morte. }\end{array}$ \\
\hline $\begin{array}{l}\text { Jandira,I21,G1 } \\
\text { Parto: normal no hospital/maternidade municipal (SUS). } \\
\text { Recém-nascido: idade gestacional } 26 \text { semanas, peso ao nascer } \\
\text { 845g, Apgar } 2 \text { e 4, sexo feminino. } \\
\text { Trabalho de parto prematuro, ruptura de membranas, feto e } \\
\text { recém-nascido afetados por outras complicações específicas } \\
\text { do trabalho de parto e parto, recém-nascido com suspeita de } \\
\text { infecção, doença da membrana hialina, prematuridade. Óbito com } \\
5 \text { dias. } \\
\text { Abril/2016. } \\
\text { Evitabilidade: sim (1.2.1 Atenção à gestação). }\end{array}$ & $\begin{array}{l}\text { Quando estava de } 5 \text { meses sentiu dores no baixo ventre e foi para o } \\
\text { hospital, onde foi internada. Falou que ficaram “enrolando" ela por } \\
3 \text { dias, que tinha dor e contração, que ficou sofrendo. O parto foi } \\
\text { normal, mas logo levaram a filha pra UTI neo, não viu nem segurou. Foi } \\
\text { transferida da maternidade para outra ala do hospital, com doentes } \\
\text { adultos até sua alta. Vinha à maternidade várias vezes ao dia. Numa } \\
\text { madrugada ligaram para ela e chegando ao hospital deram a notícia } \\
\text { do óbito. Mostraram a bebê enrolada em panos, pensa que podem } \\
\text { ter matado sua filha para liberar vaga para outra criança, pois ouviu } \\
\text { enfermeiro dizer que torcia para não ter partos prematuros, pois não } \\
\text { havia vagas para todos. }\end{array}$ \\
\hline $\begin{array}{l}\text { Dalva,I20,G4 } \\
\text { Parto: normal no hospital/maternidade municipal (SUS). } \\
\text { Recém-nascido: idade gestacional } 22 \text { semanas, peso ao nascer } \\
\text { 400g, Apgar } 4 \text { e 2, sexo feminino. } \\
\text { Hipoxia uterina não especificada, prematuridade extrema. Óbito } \\
\text { com } 2 \text { horas de vida. } \\
\text { Outubro/2015. } \\
\text { Evitabilidade: sim (1.2.1 Atenção à gestação). }\end{array}$ & $\begin{array}{l}\text { Teve dores abdominais fortes e procurou o pronto-socorro, fizeram } \\
\text { radiografia e disseram que tinha uma massa na barriga, ficou no soro } \\
\text { aguardando ultrassom. Ficou a noite toda sozinha numa maca. Sentiu } \\
\text { que estava molhada nas pernas, fez força e a filha nasceu, quase caiu no } \\
\text { chão, pois não havia ninguém acompanhando. Uma médica que estava } \\
\text { passando no corredor viu e levou a bebê para a UTI neonatal. Depois } \\
\text { vieram avisar que ela viveu por } 3 \text { horas, que devia estar com quase } 5 \\
\text { meses pois já estava formada. Por muito tempo ficou com a imagem de } \\
\text { sua filha na cabeça e disse que foi muito ruim. }\end{array}$ \\
\hline
\end{tabular}

SUS: Sistema Único de Saúde.

“...com 2 meses eles falaram que eu não podia ter relação, e eu não tive relação. Aí com 4 meses eu comecei a sangrar de novo. Aí eu fui no hospital de novo, e eles falaram que era porque ele tinha me machucado de novo... e dai eu expliquei que com 2 meses eu voltei lá e eles tinham falado que era isso, e isso não é normal. E eu vim aqui e procurei a Policlínica, e eles falaram que eu tinha que ir lá, voltar lá... que era com eles, que não era aqui" (Jandira,I21,G1).

Em ambos os casos nota-se a insuficiência de resolutividade da atenção básica em que ficaram ao longo de suas gestações. No caso de Judite,I36,G4, com obesidade, ocorreu o fluxo inverso; foi avaliada em serviço especializado e devolvida para a atenção básica. Revoltada, ela procurou consulta no convênio, quando foram identificadas outras situações de risco não vistas no serviço público, nem na unidade básica, nem no serviço especializado. Sua gestação foi complicando e ela manteve o acompanhamento pré-natal em consultas no convênio particular. Ainda que a atenção básica tenha mantido o vínculo com visitas domiciliares semanais do ACS, que estão registradas no seu prontuário, não houve nenhuma integração ou intervenção para ampliar a efetividade do cuidado. É importante destacar que no seu cartão de pré-natal e prontuário só consta o registro das consultas e exames no setor público. Não há informação registrada sobre a atenção no setor privado. 


\section{Quadro 3}

Situação da mulher após o óbito neonatal e perspectivas sobre o cuidado. Zona noroeste de Santos, São Paulo, Brasil, $2015-2016$.

\begin{tabular}{|c|c|}
\hline SITUAÇÃO DE CADA CASO APÓS O ÓBITO & PERSPECTIVAS DA MULHER SOBRE O CUIDADO \\
\hline $\begin{array}{l}\text { Katia,I33,G4 } \\
\text { Consta consulta de puerpério, realizada } 4 \text { dias após o óbito, com } \\
\text { prescrição de contraceptivo, verificação da glicemia e pressão arterial. } \\
\text { Foi feita visita domiciliar de investigação do óbito no mês seguinte ao } \\
\text { ocorrido. } \\
\text { Marido saiu de casa após o óbito da filha. No final de } 2016 \text { apresentou } \\
\text { suspeita de chikungunya, ficou internada por } 1 \text { mês entre abril e maio } \\
\text { de } 2017 \text {. Os resultados da sorologia deram inconclusivos. Ficou com } \\
\text { sequelas motoras, dificuldade de locomoção. O pai levou as crianças } \\
\text { durante a internação e ela está em disputa pela guarda. Ele a acusa de } \\
\text { abandono e maus-tratos. O primeiro marido não paga pensão dos filhos } \\
\text { adolescentes. Sem apoio familiar e com dificuldades financeiras. }\end{array}$ & $\begin{array}{l}\text { Considera que foi bem assistida na saúde, quando gestante. Refere } \\
\text { que recebe sempre as visitas da agente comunitária de saúde. No } \\
\text { momento, aguarda para ser atendida por reumatologista e não tem } \\
\text { acesso ao remédio que foi prescrito no hospital pelo alto custo. } \\
\text { Sabe que tem de se alimentar bem, mas nem sempre consegue } \\
\text { comprar frutas e verduras, que têm as vitaminas que precisa. } \\
\text { Quer melhorar para poder trabalhar e conseguir seus filhos de } \\
\text { volta. }\end{array}$ \\
\hline $\begin{array}{l}\text { Milena,I33,G6 } \\
\text { Não há registro de consulta de puerpério. Não foi feita visita domiciliar } \\
\text { de verificação de óbito (ela não aceitou pois na época não queria } \\
\text { conversar sobre o ocorrido e tinha feito tudo pelo convênio). Há } \\
\text { registros de dois atendimentos na atenção básica, um em 2016, em que } \\
\text { consta a realização de exame de gravidez que deu negativo, e outro } \\
\text { em 2017, com verificação de pressão e glicemia. Mas não há menção à } \\
\text { orientação sobre planejamento reprodutivo. } \\
\text { Tem medo de outra gestação, médico do convênio disse que se ela } \\
\text { engravidar pode morrer; sugeriu que o marido operasse, mas ele não } \\
\text { quer fazer vasectomia. Usam pílula e preservativo. }\end{array}$ & $\begin{array}{l}\text { Acha que fazem poucos exames, que teriam de considerar seu } \\
\text { antecedente e ter mais cuidado, fazer mais exames no início } \\
\text { (medida de colo uterino). Na gestação anterior chegou a procurar } \\
\text { a unidade básica em seu bairro, mas a médica a mandou para a } \\
\text { maternidade municipal e ela não quis, pois ouvia falar muito mal } \\
\text { do hospital. Depois soube do hospital público para gestação de alto } \\
\text { risco e que era muito bom, mas continuou no convênio, mesmo } \\
\text { preocupada com o limite de carência para internação na UTI } \\
\text { neonatal. } \\
\text { Quer cuidar das filhas e dar futuro pra elas. }\end{array}$ \\
\hline $\begin{array}{l}\text { Judite,I36,G4 } \\
\text { Não há registro de consulta de puerpério. Foi feita visita domiciliar de } \\
\text { verificação de óbito. Ficou muito deprimida, foi à psiquiatra e psicólogo } \\
\text { pelo convênio e tomou medicação; quis parar e o medico encaminhou } \\
\text { para fazer atividades. Procurou centro de convivência de idosos, teve de } \\
\text { pedir autorização na prefeitura e Secretaria de Assistência Social para } \\
\text { participar das atividades. Frequenta semanalmente e gosta muito. } \\
\text { Quis emagrecer e tomou remédios por conta própria. Passou mal e } \\
\text { decidiu procurar serviço pelo convênio para fazer cirurgia bariátrica. }\end{array}$ & $\begin{array}{l}\text { Acha que tem de ter mais exames e mais frequência de consultas, } \\
\text { para acompanhar melhor a gestante, ver se tem algum problema } \\
\text { e saber como está o bebê. Criticou a atenção secundária, que a } \\
\text { devolveu para a atenção básica. } \\
\text { Acha que sua gordura teve a ver com a morte do filho. Aguarda a } \\
\text { cirurgia bariátrica pelo convênio. E depois quer fazer atividade física } \\
\text { no centro de convivência. } \\
\text { Quer engravidar novamente em } 2018 \text { e fazer pré-natal na unidade } \\
\text { básica onde já conhece todos os funcionários. }\end{array}$ \\
\hline $\begin{array}{l}\text { Silmara,I29,G2 } \\
\text { Não há registro de consulta de puerpério. Foi feita visita domiciliar de } \\
\text { verificação de óbito após } 1 \text { mês. } \\
\text { Relata que na atenção básica falaram sobre colocar o implante } \\
\text { hormonal, mas tinha a questão da pressão arterial elevada. Foi } \\
\text { encaminhada para colocar o DIU, mas enquanto aguardava engravidou } \\
\text { novamente no inicio de } 2016 \text {. Foi encaminhada para pré-natal de alto } \\
\text { risco mas teve um aborto, por aumento súbito de pressão; houve risco } \\
\text { de óbito materno, precisou ficar internada } 3 \text { dias para estabilizar a } \\
\text { pressão e fazer curetagem. } \\
\text { Conseguiu o DIU há } 6 \text { meses e se adaptou bem, vai às consultas de } \\
\text { rotina na atenção básica. Toma } 3 \text { medicações para o controle da } \\
\text { hipertensão. Teve um episódio de convulsão, precisou ser internada e } \\
\text { aguarda para fazer exames de imagem e passar por neurologista. }\end{array}$ & $\begin{array}{l}\text { Compara o cuidado que recebeu na primeira gestação quando ficou } \\
\text { internada por } 3 \text { meses e sentia-se "em casa”, pois conhecia todos, } \\
\text { funcionários e pacientes, além de sua família estar próxima e visitá- } \\
\text { la sempre porque a maternidade ficava no bairro de sua residência. } \\
\text { Sobre o parto e internação de seu segundo filho na UTI neonatal de } \\
\text { um hospital em outro município, relatou que só podia ir para casa } \\
\text { quando seu tio a levava nos finais de semana e que a distância foi } \\
\text { difícil. } \\
\text { Quer se cuidar para poder cuidar da filha. } \\
\text { Manifestou preocupação com a situação no Brasil e o futuro do } \\
\text { SUS. }\end{array}$ \\
\hline
\end{tabular}

(continua) 


\begin{tabular}{|c|c|}
\hline SITUAÇÃO DE CADA CASO APÓS O ÓBITO & PERSPECTIVAS DA MULHER SOBRE O CUIDADO \\
\hline $\begin{array}{l}\text { Juçara,129,G2 } \\
\text { Após o parto ficou internada durante } 7 \text { dias para tratar infecção com } \\
\text { antibiótico. E depois na alta informaram que estava tudo bem com o } \\
\text { útero dela e que poderia engravidar dali a } 6 \text { meses, se quisesse. Há } \\
\text { registro de consulta de puerpério aos } 20 \text { dias pós-óbito, com prescrição } \\
\text { de contracepção oral. Foi feita visita domiciliar de verificação do óbito } \\
\text { antes de completar } 1 \text { mês. } \\
\text { Estava grávida no dia da entrevista em 2017. Até aquele momento suas } \\
\text { consultas foram na atenção básica. }\end{array}$ & $\begin{array}{l}\text { Não entendeu o que aconteceu, pois tinha feito exames e } \\
\text { tratamento da infecção no pré-natal. Foi pesquisar na Internet por } \\
\text { que as mulheres têm filho prematuro e viu que se a mulher tem } \\
\text { uma bactéria muito forte pode causar uma dilatação do útero e ela } \\
\text { ter o parto prematuro. } \\
\text { Sobre a gestação atual, falou que vai perguntar tudo para a médica, } \\
\text { sobre como está seu útero, se vai aguentar até os } 6 \text { meses, se terá } \\
\text { de ficar de repouso e sobre descolamento de placenta. Quer ser } \\
\text { bem cuidada e sair com o filho nos braços. }\end{array}$ \\
\hline $\begin{array}{l}\text { Roberta,I39,G3 } \\
\text { Há registro de tentativa de visita para a investigação do óbito, mas } \\
\text { não a encontraram na residência. Por telefone souberam que ela } \\
\text { acompanhava a outra gemelar, que nem chegou a sair da UTI neonatal } \\
\text { e faleceu com } 3 \text { meses. } \\
\text { Passou em consulta na atenção básica, onde consta que está } \\
\text { "emocionalmente tranquila", triste mas aceitando como "vontade de } \\
\text { Deus"; há registro de valor de pressão aumentado e que foi prescrita } \\
\text { pílula anticoncepcional e necessidade de controle da pressão. Continua } \\
\text { frequentando a unidade para consultas e exames. }\end{array}$ & $\begin{array}{l}\text { Relaciona seu parto prematuro a esforço pelo trabalho doméstico e } \\
\text { por andar de bicicleta. } \\
\text { Acredita que tem de ter mais orientação da área da saúde sobre o } \\
\text { que a gestante pode ou não fazer, atividades físicas e alimentação, } \\
\text { para evitar o parto prematuro. } \\
\text { Quer engravidar. Está nas mãos de Deus. Acha que cada gravidez } \\
\text { é diferente da outra. Se conseguir ter um ou gêmeos quer fazer } \\
\text { laqueadura para não ter mais. }\end{array}$ \\
\hline $\begin{array}{l}\text { Jandira,I21,G1 } \\
\text { Não foi avaliada em consulta médica de puerpério, só mediram pressão } \\
\text { e aplicaram contraceptivo injetável, que ela não queria tomar. } \\
\text { Foi feita visita domiciliar de verificação de óbito. } \\
\text { Não voltou para nova injeção, engravidou depois de } 4 \text { meses e "levou } \\
\text { bronca" da médica. } \\
\text { Teve uma filha, em } 2017 \text {, nasceu com } 39 \text { semanas e mais de 3kg, no } \\
\text { hospital regional de referência para alto risco, de parto normal. Está } \\
\text { com } 3 \text { meses, com dificuldades na amamentação. } \\
\text { Está usando preservativo, pois a injeção engorda. }\end{array}$ & $\begin{array}{l}\text { Fez muitas queixas a todo cuidado que recebeu na maternidade } \\
\text { municipal, que não souberam conversar nem explicar nada sobre } \\
\text { o que aconteceu, desde sua internação até o óbito da filha, ainda } \\
\text { mais por ela e seu companheiro serem jovens. Fica muito triste } \\
\text { quando precisa ir ao hospital e lembra como foi tratada. } \\
\text { Sobre a atenção básica, ficou com raiva da médica que disse que } \\
\text { era normal o sangramento e depois a mandou para o hospital. } \\
\text { Neste momento queria ter mais apoio para a amamentação e falou } \\
\text { que queria colocar o DIU, mas só lhe oferecem o contraceptivo } \\
\text { injetável. }\end{array}$ \\
\hline $\begin{array}{l}\text { Dalva,I20,G4 } \\
\text { Não há registro de consulta de puerpério, mas refere que frequenta a } \\
\text { atenção básica para exames e aplicação de contraceptivo injetável. } \\
\text { Foi feita visita domiciliar de verificação de óbito. } \\
\text { Separou-se de um novo companheiro por violência verbal. } \\
\text { Vive com a filha de } 3 \text { anos em casa de amiga. } \\
\text { Está fumando muito, refere que o médico já lhe avisou que o } \\
\text { anticoncepcional é muito forte e do risco de trombose. }\end{array}$ & $\begin{array}{l}\text { Elogiou a unidade da atenção básica, tem tudo: consultas, exames, } \\
\text { remédios e "não paga"; e considera o hospital regional de referência } \\
\text { "o melhor". } \\
\text { Falou sobre mais oportunidades para as mulheres, pra que não } \\
\text { pensassem só em ter filho. } \\
\text { Quer trabalhar e voltar a estudar. }\end{array}$ \\
\hline
\end{tabular}

DIU: dispositivo intrauterino; SUS: Sistema Único de Saúde.

"A doutora me mandou... por mais que não tenha pressão alta, não tenha diabete... eu sou uma gordura mórbida, eu posso acarretar no decorrer da gravidez. 'Não, não, você não tem nada, você está boa, faz a dieta de boca, faz caminhada, você está boa.' Vim para cá, eu sei que começou um empurra para cá, empurra para lá... falei: 'sabe de uma coisa?, vou para o convênio', que eu já tinha o convênio, mas como sempre gostei daqui... então o convênio só usava mesmo para fazer exames, que era mais rápido" (Judite,I36,G4).

Milena,I33,G6 e Roberta,I39,G3 fizeram pré-natal exclusivamente no setor privado e não receberam o cartão de pré-natal. Nem nos processos do setor de vigilância, após o óbito, há registro de suas consultas e exames. Roberta,I39,G3 passou por quatro serviços distintos, maternidade pública, 
consulta de pré-natal no convênio, hospital para gestação de alto risco e maternidade do convênio. Em seu relato disse que durante a primeira internação na maternidade pública pelo sangramento não avaliaram sua pressão e nem a medicaram; "cuidaram só do sangramento".

No Quadro 2, verifica-se que houve sete casos de partos prematuros, entre 20 e 29 semanas de gestação, e que todos foram considerados evitáveis por adequada atenção à gestação. Destacam-se os casos de Jandira,I21,G1, Juçara,I29,G2 e Dalva,I20,G4 porque foram partos vaginais, em que aconteceram importantes situações de pouco acolhimento e cuidado.

Houve dois casos de transferência de hospital na ocasião do parto que se relacionaram à garantia de vaga na UTI neonatal. Essa questão assumiu outras proporções para Jandira,I21,G1, que a associa ao óbito de sua filha.

No Quadro 3, que apresenta a situação da mulher após o óbito neonatal, verifica-se que somente em dois casos houve registro da consulta de puerpério, realizada em tempo oportuno na atenção básica. A ausência de registro da atenção no setor privado não nos possibilitou saber se Milena,I33,G6, Judite,I36,G4 e Roberta,I39,G3 foram atendidas no puerpério.

O caso de Silmara,I29,G2 talvez seja o mais alarmante, uma vez que "lembrou ao médico" que não podia utilizar métodos hormonais pela sua hipertensão, e enquanto "esperava o DIU" engravidou novamente e teve um novo óbito, desta vez fetal, no qual ela própria correu risco de morte.

Finalmente, há que se analisar como ficaram essas mulheres após a experiência vivida, destacando-se os casos de: Judite,I36,G4, que teve de pedir autorização na prefeitura para participar de um grupo de idosos e superar a depressão; Katia,I33,G4, que teve sérios problemas de saúde, com sequelas de uma doença relacionada à vulnerabilidade ambiental do local onde vive e sem condições de trabalhar; Dalva,I20,G4, que não consegue parar de fumar e claramente precisa de um apoio para enfrentar seu passado de violência por parceiro íntimo, relato nunca registrado nos serviços de saúde e possivelmente revelado pela primeira vez em nossa entrevista. Quanto à visita domiciliar de verificação do óbito, somente Milena,I33,G6 a recusou. Em todos os demais casos foram realizadas.

\section{Discussão}

\section{As mulheres, vulnerabilidades, gestação e riscos}

Para ampliar a compreensão de situações que podem se relacionar ao cuidado das mulheres e ao óbito neonatal, inicialmente importa considerar sua vulnerabilidade. Reconhecendo as três dimensões dessa vulnerabilidade, a social, a programática e a individual 4, deve-se considerar como o contexto social e as condições de acolhimento e acesso aos serviços se entrelaçam com condições de maior risco individual.

Conforme revelam estudos com análise dos diferenciais intraurbanos em outras localidades brasileiras, há impacto da condição de vida nos índices de mortalidade infantil, mais evidentes no componente pós-neonatal, mas também verificado no período peri e neonatal, possivelmente relacionado à sobreposição entre os fatores socioeconômicos e o acesso e qualidade no planejamento da gestação, na assistência ao pré-natal, parto e ao recém-nascido 18,19,20.

Quanto à questão racial, no Brasil há os maiores índices de mortalidade infantil e a pior atenção pré-natal e ao parto para mulheres pardas e pretas, como aponta a literatura $21,22,23$, o que incide diretamente no caso de nossas entrevistadas. Soma-se, pois, às condições desfavoráveis do ponto de vista da classe social das mulheres, a condição étnica e racial, ampliando suas vulnerabilidades individuais.

Na pesquisa Nascer no Brasil, menos da metade das puérperas referiram ter planejado a gestação atual e 30\% não queriam engravidar 24 . Também entre gestantes de alto risco e mulheres que vivenciaram o óbito infantil houve relatos da gestação indesejada, com incompreensão dos perigos a que estão sujeitas e desconhecimento de recursos e cuidados, por acontecerem em uso de contracepção ou por se acreditarem inférteis 7,8 . Chama a atenção que o método contraceptivo de escolha para essas mulheres tenha sido o hormonal, considerando seu histórico reprodutivo e insatisfação com o uso. Além de ser inadequado para mulheres com antecedentes clínicos, como a hipertensão arterial e diabetes, demonstrando a pouca atenção dos profissionais quanto ao planejamento reprodutivo ${ }^{7}$. Assim, esses dados da literatura compõem perfeitamente com o quadro que identificamos de situações 
reprodutivas de nossas entrevistadas. Cabe aqui, então, destacar em especial a altíssima taxa já apontada nessa literatura quanto à "gravidez indesejada", questão pouco considerada nos estudos acerca da mortalidade neonatal, seja como variável de questionários em estudos quantitativos, seja como categoria em estudos qualitativos.

De outro lado, há que se levar em conta que se consideram fatores de risco gestacionais, condições preexistentes ou que se manifestam ao longo da gestação, que levam a uma maior probabilidade de evolução desfavorável, implicando riscos para a mãe e para o feto. A assistência pré-natal pressupõe avaliação dinâmica dessas situações de risco e uma prontidão de resposta dos serviços para identificar problemas de forma a poder atuar rapidamente. Assim sendo, a classificação do risco é uma das estratégias que orientaria a organização do cuidado pré-natal 25. Contudo, se a classificação de risco foi ao menos tentada, não foi observado em nossa pesquisa uma relação com a prontidão de resposta esperada por parte dos serviços.

\section{Assistência pré-natal: domínio de competência e relações público-privado}

Os casos demonstram que ter acesso a consultas e exames não é garantia de efetividade e resolução dos problemas. Considerar somente indicadores de cobertura, captação precoce e realização de procedimentos para avaliar a qualidade do pré-natal tem limitações, justamente por não dar visibilidade ao cuidado realmente ofertado e aos problemas na assistência. Avaliação semelhante sobre a qualidade do pré-natal foi apontada por mulheres que vivenciaram óbitos fetais e infantis, com início no primeiro trimestre e número elevado de consultas, mas com críticas ao atendimento recebido pela falta de adequado exame físico, precariedade da comunicação e falta de compromisso dos profissionais de saúde com a continuidade do cuidado, caracterizando o "jogo de empurra" 7,8.

Nossos achados mostram que quando houve encaminhamento para outro nível de atenção, além de não ter sido feito em tempo oportuno, não houve integração e nem resolubilidade no cuidado. Essas situações revelam pelo menos três questões centrais que precisarão ser enfrentadas para uma real garantia de integralidade do cuidado: o trabalho articulado em rede, a disponibilidade de informações e a relação público-privado.

Sobre o trabalho em rede, conforme apontam Cecilio et al. 26 , ainda que de acordo com a política vigente a atenção básica deve ser a ordenadora do cuidado de saúde, tal atenção não reúne as condições materiais e simbólicas para realizá-lo, especialmente quando as condições de vulnerabilidade exigem arranjos mais complexos para a responsabilização e gestão do cuidado. No estudo desses autores, assim como relataram nossas entrevistadas, foram os usuários, com base nas suas distintas experiências de encontro ou desencontro com os serviços de saúde, que construíram novos agenciamentos para conseguir o acesso à rede de serviços.

Outro aspecto relacionado à possibilidade de um cuidado compartilhado e contínuo é a disponibilidade da informação. Apesar de existirem instrumentos como o cartão da gestante para permitir o registro do acompanhamento da mulher, um estudo de abrangência nacional encontrou que apenas $70 \%$ delas o apresentaram na admissão hospitalar e somente entre 40 e $60 \%$ dos cartões analisados contavam com registro da segunda glicemia e do exame de ultrassonografia 24.

Tornando a situação ainda mais difícil, verifica-se que cada indivíduo usuário da saúde pode fazer uso, quer da assistência pública, quer da privada, sem que necessariamente exista uma articulação das ações desenvolvidas em cada uma ou alguma forma de interação entre os serviços. Embora o acesso aos diferentes serviços exista, a questão poderia ser pensada em termos de qual dos setores terá o domínio de competências para a gestão do cuidado, o que vem sendo feito pelo próprio paciente sem que os serviços tenham acesso a todas as informações sobre a assistência prestada 27 . Afinal, a literatura já aponta para a necessidade de processos que fortaleçam a regulação, avaliações, monitoramento e auditorias para garantir padrão semelhante de atenção a todos os usuários, visando à inserção efetiva do setor privado numa rede regionalizada e racionalizada de serviços de saúde 28 . 


\section{O parto}

Nossos dados apontam entre todas as entrevistadas a ocorrência de partos prematuros, condição que espelha novamente e por outro ângulo a somatória de vulnerabilidades que essas mulheres enfrentam. Em sentido oposto, como achado positivo, temos o acesso para a atenção ao parto, pois não houve peregrinação das mulheres em mais de um serviço, situação que vem sendo apontada ainda como um desafio em diversas localidades do país e que está associada ao óbito neonatal 3. Por outro lado, as situações de transferências que registramos neste estudo, ainda que realizadas pelo hospital que acolheu as mulheres, evidenciam a necessidade de um real dimensionamento e regulação assistencial para garantir a retaguarda vinculada ao hospital onde será o parto, permitindo ao recém-nascido de risco a continuidade de cuidados que se fizerem necessários, caracterizando o nascimento como tendo sido realizado em local adequado 3 .

Outro evento relacionado ao acolhimento e cuidado no parto é o próprio parir. Nossos dados mostram relatos negativos, sobretudo quando os partos foram pela via vaginal.

O estudo Nascer no Brasil encontrou que a fonte de pagamento privado foi associada ao menor relato de violência e mais respeito, privacidade, clareza nas explicações, possibilidade de fazer perguntas e participar das decisões. Tal situação denuncia a existência de uma cultura discriminatória dos profissionais de saúde com as mulheres atendidas no setor público, tidas como incapazes de compreender e decidir sobre intervenções no parto. Porém, independentemente de tratar-se do setor público ou privado, passar pelo trabalho de parto vaginal, como ocorreu com as mulheres de nosso estudo, associou-se a menores níveis de respeito, privacidade e maior relato de violência, evidenciando práticas assistenciais inadequadas 23 .

\section{E a vida continua...: a mulher e seu cuidado no pós-parto}

Considerando que as mulheres já se encontravam em situação de vulnerabilidade e riscos, após este desfecho do óbito neonatal esperava-se maior preocupação e priorização de seu cuidado. No período de puerpério há novas situações que contribuem para aumentar a vulnerabilidade da mulher, relacionadas a questões físicas e dificuldades emocionais 29 , o que para estas mulheres foi acentuado pela morte de seus filhos.

Se avaliarmos o cuidado somente pela perspectiva da contracepção ofertada, identificam-se os mesmos problemas apontados anteriormente quanto à inadequação e insatisfação com o método. Mas se ampliarmos o olhar para outras necessidades das mulheres, neste caso decorrentes da experiência de um óbito neonatal, identificam-se questões complexas envolvendo aspectos da saúde física e também mental, que revelam as dificuldades do cuidado e o desafio da ação intersetorial para possibilitar uma atenção integral relativa ao pós-parto.

\section{Considerações finais}

Este trabalho aponta para as iniquidades em saúde relativas às políticas públicas quando se toma a distribuição socioespacial no interior de uma região ou município dado, o que nos obriga a pensar políticas diferenciadas no sentido de diminuir as desigualdades internas a um dado território. Esta é a importância da realização de estudos locais.

As histórias das mulheres da zona noroeste de Santos que vivenciaram o óbito neonatal revelam que a integralidade do cuidado está muito distante. A vulnerabilidade em seu todo não é considerada na organização do cuidado: não há integração entre os serviços e entre as equipes profissionais, e o processo de trabalho não possibilita a resolubilidade de problemas quando diante de situações tão delicadas e complexas como as que tratamos. E a complexidade abarca não apenas o uso dos serviços, mas a integralidade clínico-assistencial, em termos da saúde física e mental dos cuidados necessários a cada usuária.

Há que se lembrar o fato de que há um setor de vigilância em saúde com previsão de ações quando ocorrem os óbitos infantis. Todavia, observou-se neste estudo um papel restrito e isolado dessas ações, que pode ser traduzido em um registro meramente formal do ocorrido, assumindo a ação em saúde 
um papel apenas burocrático. Um aspecto já de imediato pode ser destacado, qual seja uma maior integração do serviço de vigilância juntamente aos comitês de investigação dos óbitos maternos e infantis e aos demais serviços assistenciais, promovendo a aproximação dos profissionais envolvidos 6 . Tal aproximação teria como objetivo discutir e planejar ações articuladas, bem como a interação intersubjetiva desses profissionais, em termos de formular um programa ou projeto assistencial em comum, tal qual recomenda a literatura que trata da integração do trabalho em equipe e da integração do trabalho em rede em outras modalidades de situações assistenciais envolvendo a saúde da mulher 30 . Em nosso caso, como uma perspectiva, especialmente para essas mulheres, o comitê de prevenção ao óbito materno e infantil, no âmbito das ações de vigilância em saúde, deveria ser fortalecido e instrumentalizado para assumir um papel de gestão do cuidado junto às equipes de saúde assistenciais e numa perspectiva intersetorial.

\section{Colaboradores}

M. U. Devincenzi e L. B. Schraiber participaram da concepção do projeto, análise e interpretação dos dados, redação do artigo, revisão crítica relevante do conteúdo intelectual e aprovação final da versão a ser publicada e são responsáveis por todos os aspectos do trabalho na garantia da exatidão e integridade de qualquer parte.

\section{Informações adicionais}

ORCID: Macarena Urrestarazu Devincenzi (00000001-9425-1625); Lilia Blima Schraiber (00000002-3326-0824).

\section{Agradecimentos}

À Fundação de Amparo à Pesquisa do Estado de São Paulo (FAPESP), pelo apoio via auxílio regular à pesquisa (processo 2017/14050-0). À Silvia de Almeida Mendes Andrade, enfermeira da Secretaria Municipal de Saúde de Santos, pelo apoio no trabalho de campo.

\section{Referências}

1. Ceccon RF, Bueno ALM, Hesler LZ, Kirsten KS, Portes VM, Viecili PRN. Mortalidade infantil e saúde da família nas unidades da Federação brasileira, 1998-2008. Cad Saúde Colet (Rio J.) 2014; 22:177-83.

2. Pinheiro R, Mattos RA, organizadores. Os sentidos da integralidade na atenção e no cuidado à saúde. Rio de Janeiro: Instituto de Medicina Social, Universidade do Estado do Rio de Janeiro/Abrasco; 2001

3. Lansky S, Friche AAL, Silva AAM, Campos D, Bittencourt SDA, Carvalho ML, et al. Pesquisa Nascer no Brasil: perfil da mortalidade neonatal e avaliação da assistência à gestante e ao recém-nascido. Cad Saúde Pública 2014; 30 Suppl 1:S192-207.

4. Ayres JRCM, França Júnior I, Calazans GJ, Saletti Filho HC. O conceito de vulnerabilidade e as práticas de saúde: novas perspectivas e desafios. In: Czeresnia D, Freitas CM, organizadores. Promoção da saúde: conceitos, reflexões, tendências. Rio de Janeiro: Editora Fiocruz; 2003. p. 117-39.

5. Venâncio SI, Paiva R. O processo de implantação dos comitês de investigação do óbito infantil no Estado de São Paulo. Rev Bras Saúde Mater Infant 2010; 10:369-75.

6. Fernandes RZS, Vilela MFG. Estratégias de integração das práticas assistenciais de saúde e de vigilância sanitária no contexto de implementação da Rede Cegonha. Ciênc Saúde Colet 2014; 19:4457-66.

7. Oliveira DC, Mandu ENT. Mulheres com gravidez de maior risco: vivências e percepções de necessidades e cuidado. Esc Anna Nery Rev Enferm 2015; 19:93-101.

8. Xavier RB, Bonan C, Silva KS, Nakano AR Itinerários de cuidados à saúde de mulheres com história de síndromes hipertensivas na gestação. Interface (Botucatu, Online) 2015; 19:1109-20. 
9. Goulart LMHF, Somarriba MG, Xavier CC A perspectiva das mães sobre o óbito infantil: uma investigação além dos números. Cad Saúde Pública 2005; 21:715-23.

10. Santos ALD, Rosenburg CP, Buralli KO. Histórias de perdas fetais contadas por mulheres: estudo de análise qualitativa. Rev Saúde Pública 2004; 38:268-76.

11. Almeida MCS, Gomes CMS, Nascimento LFC. Análise espacial da mortalidade neonatal no Estado de São Paulo, 2006-2010. Rev Paul Pediatr 2014; 32:374-80.

12. Merola VFM. Os portos na nova economia global: uma proposta de gestão ambiental estratégica para a promoção da sustentabilidade e da saúde em cidades portuárias [Tese de Doutorado]. São Paulo: Universidade de São Paulo; 2017.

13. Fernandes F. Ensaios de sociologia geral e aplicada. São Paulo: Editora Pioneira; 1971.

14. Camargo A. Os usos da história oral e da história de vida: trabalhando com elites políticas. Dados Rev Ciênc Sociais 1984; 27:5-28.

15. Queiroz MIP. Relatos orais: do indizível ao dizível. Ciênc Cult 1987; 39:272-86.

16. Malta DC, Sardinha LMV, Moura L, Lansky S, Leal MC, Szwarcwald CL, et al. Atualização da lista de causas de mortes evitáveis por intervenções do Sistema Único de Saúde do Brasil. Epidemiol Serv Saúde 2010; 19:173-6.

17. Minayo MCS. O desafio do conhecimento: pesquisa qualitativa em saúde. 14a Ed. São Paulo: Editora Hucitec; 2014.

18. Morais Neto OL, Barros MBA, Martelli CMT, Silva SA, Cavenaghi SM, Siqueira Jr. JB. Diferenças no padrão de ocorrência da mortalidade neonatal e pós-neonatal no Município de Goiânia, Brasil, 1992-1996: análise espacial para identificação das áreas de risco. Cad Saúde Pública 2001; 17:1241-50.

19. Guimarães MJB, Marques NM, Melo Filho DA, Szwarcwald CL. Condição de vida e mortalidade infantil: diferenciais intra-urbanos no Recife, Pernambuco, Brasil. Cad Saúde Pública 2003; 19:1413-24.

20. Martins EF, Rezende EM, Almeida MCM, Lana FCF. Mortalidade perinatal e desigualdades socioespaciais. Rev Latinoam Enferm 2013; 21:1062-70.

21. Caldas ADR, Santos RV, Borges GM, Valente JG, Portela MC, Marinho GL. Mortalidade infantil segundo cor ou raça com base no Censo Demográfico de 2010 e nos sistemas nacionais de informação em saúde no Brasil. Cad Saúde Pública 2017; 33:e00046516.
22. Leal MC, Gama SGN, Pereira APE, Pacheco VE, Carmo CN, Santos RV. A cor da dor: iniquidades raciais na atenção pré-natal e ao parto no Brasil. Cad Saúde Pública 2017; 33 Suppl 1:e00078816.

23. d'Orsi E, Brüggemann OM, Diniz CSG, Aguiar JM, Gusman CR, Torres JA, et al. Desigualdades sociais e satisfação das mulheres com atendimento ao parto no Brasil: estudo nacional de base hospitalar. Cad Saúde Pública 2014; 30 Suppl:S154-68.

24. Viellas EF, Domingues RMSM, Dias MAB, Gama SGN, Theme Filha MM, Costa JV, et al. Assistência pré-natal no Brasil. Cad Saúde Pública 2014; 30 Suppl:S85-100.

25. Departamento de Ações Programáticas Estratégicas, Secretaria de Atenção à Saúde, Ministério da Saúde. Gestação de alto risco: manual técnico. 5a Ed. Brasília: Editora MS; 2012. (Série A. Normas e Manuais Técnicos).

26. Cecilio LCO, Andreazza R, Carapinheiro G, Araújo EC, Oliveira LA, Andrade MGG, et al. A atenção básica à saúde e a construção das redes temáticas de saúde: qual pode ser o seu papel? Ciênc Saúde Colet 2012; 17:2893-902.

27. Meneses CS, Cecilio LCO, Andreazza R, Carapinheiro G, Andrade MGG, Santiago SM, et al. $\mathrm{O}$ agir leigo e a produção de mapas de cuidado mistos público-privados. Ciênc Saúde Colet 2017; 22:2013-24.

28. Gryschek ALFPL, Nichiata LYI , Fracolli LA, Oliveira MAF, Pinho PH. Tecendo a rede de atenção à saúde da mulher em direção à construção da linha de cuidado da gestante e puérpera, no Colegiado de Gestão Regional do Alto Capivari - São Paulo. Saúde Soc 2014; 23:689700.

29. Corrêa MSM, Feliciano KVO, Pedrosa EM, Souza AI. Acolhimento no cuidado à saúde da mulher no puerpério. Cad Saúde Pública 2017; 33:e00136215.

30. Schraiber LB, d'Oliveira AFPL, Hanada H, Kiss L. Assistência a mulheres em situação de violência - da trama de serviços à rede intersetorial. Athenea Digital 2012; 12:237-54. 


\section{Abstract}

The study analyzed the life and healthcare stories of women living in the Northwest Zone of the city of Santos, São Paulo State, Brazil, who had experienced neonatal deaths between January 2015 and July 2016. The study used triangulation of data from documents from the surveillance division, field diaries from visits to services, and interviews with the women. The interviews provided the main body of empirical data, based on narratives of the women's sexual and reproductive history, prenatal care, childbirth, and the experience of neonatal death. Of the 15 eligible cases, 8 women were interviewed, 6 of whom over 30 years of age and 2 under 30 years, all African-Brazilians, natives of Santos, and working in unskilled occupations. The data yielded the following results: (1) histories of unplanned pregnancies with various gestational risk factors; (2) the women's acknowledgment that they had experienced good access to health services; (3) questions concerning the need for tests and test results, understanding of complications, explanation of treatment approaches, and referrals; (4) prematurity, present in all the cases; (5) pain during labor, abandonment, and transfer to other services due to lack of beds in the neonatal ICU; (6) lack of integration between levels of care; and (7) after the infant's death, limited approaches and little orientation on comprehensive care related to the neonatal death. In conclusion, although the prenatal care was positively rated by the women, there was no comprehensive care for them in relation to the experience of neonatal death, with dialogue and an offer of more adequate contraceptive methods given their health history, as well as counseling on the emotional distress resulting from these experiences.

Comprehensive Health Care; Infant Mortality; Women; Qualitative Research; Integrality in Health

\section{Resumen}

El estudio analizó la trayectoria de vida y cuidado de mujeres, residentes en la zona noroeste del municipio de Santos, estado de São Paulo, Brasil, que pasaron por la experiencia de muertes neonatales, de enero de 2015 a julio de 2016. Se realizó una triangulación de datos con documentos de la sección de vigilancia, diarios de campo de visitas a los servicios de salud y entrevistas con las mujeres. Estas constituyeron el principal eje de la producción de datos empíricos, a través de relatos sobre su historial sexual y reproductivo, cuidado prenatal, momento del parto y experiencia de muerte neonatal. De los 15 casos elegibles, se entrevistaron a 8 mujeres, 6 con más y 2 con menos de 30 años, negras, oriundas de Santos, en ocupaciones de baja cualificación. Como resultados del conjunto de datos se observaron: (1) historiales de embarazos no deseados y diversos factores de riesgo gestacionales; (2) reconocimiento de las mujeres que tuvieron un buen acceso a los servicios de salud; (3) interrogantes relacionados con: necesidad de exámenes y seguimiento, valoración de complicaciones, aclaración de conductas y derivaciones a otros servicios; (4) prematuridad, implicada en todos los casos; (5) sobre el parto, relatan dolor, abandono y traslados por falta de camas en UCI neonatal; (6) falta de integración entre los niveles de atención; y (7) tras el fallecimiento, existen planteamientos limitados y poco orientados a una atención integral, relacionada con el evento del óbito neonatal. Se concluye que aunque el cuidado prenatal haya sido bien evaluado por las mujeres, no se verifica, en cuanto a la experiencia de la muerte neonatal, un cuidado integral hacia esas mujeres, con un diálogo y oferta de métodos contraceptivos más adecuados a su historial, o en relación al sufrimiento mental resultante de esas experiencias.

Atención Integral de Salud; Mortalidad Infantil; Mujeres; Investigación Cualitativa; Integralidad en Salud
Recebido em 23/Abr/2018

Versão final reapresentada em 19/Dez/2018

Aprovado em 04/Abr/2019 